\title{
Mineral processing of low quality zircon concentrates and preconcentrates
}

\author{
S. Sabedot ${ }^{1}$, H. Wotruba ${ }^{2}$, C. H. Sampaio ${ }^{3}$, C. O. Petter ${ }^{3}$ and I. A. S. de Brum ${ }^{* 3}$ \\ In NE Brazil, Millennium Inorganic Chemicals do Brasil S/A produces zircon concentrates with \\ variable contents of $\mathrm{ZrO}_{2}$. One of such concentrates, named zirconite $\mathrm{B}$, presents a low $\mathrm{ZrO}_{2}$ \\ value and high content of contaminants, being considered as a low quality concentrate. The \\ deposit consists of coastal dunes, and the minerals are located in the base, coated by a clayey- \\ ferruginous pellicle, which interferes in the zircon beneficiation. Besides, two other causes \\ influence the production of the low quality concentrate: mineral inclusions and the development of \\ metamictes in the zircons. The present work, conducted on the zirconite B concentrate and in the \\ preconcentrate, characterises the pellicle's nature, identifies the mineral inclusions in the zircons, \\ illustrates the occurrence of metamictes in the zircons and suggest alternative routes to the \\ production of a high quality zircon good, from the zirconite B concentrate and the zircon's \\ preconcentrate.
}

Keywords: Mineral processing, Zircon, Ilmenite, Tailings

\section{Introduction}

The zircon is an accessory mineral in a variety of igneous rocks, especially in those containing sodic feldspars, such as granite, senate and diorite. This mineral is one of the first to crystallise in the cooling of magma and in some cases, incorporates inclusions. Zircon is found in metamorphic rocks like gneisses and schist. Owing to the rare occurrence in the primary rocks, zircon has cconomic relevance in sedimentary deposits (mineral sands), where it appears with ilmenite, rutile, staurolite, monazite and other high density. ${ }^{1-4}$

Mineral sands' deposits are common in the seacoast in many countries. Australia concentrates the biggest reserves and it is at the same time the world's largest producer and exporter of zircon concentrate. In 2001, Brazilian reserves were equal to $3.4 \%$ of the world's and the amount produced in the country ( 21 thousand tons) represented $2 \cdot 2 \%$ of the world's production. Millennium Inorganic Chemicals do Brasil S/A produced around 11 thousand tons, exclusively destined to the domestic market. ${ }^{5}$

In the majority of the producing countries, the more interesting deposits from the economical point of view arc unconsolidated or partially consolidated placers. The processing of the run of mine (ROM) ore removes quartz and other light minerals. In the size classification, Reichert cones, spirals or other hydraulic classification devices are used. In some deposits, a step of attrition is

${ }^{1}$ Centro Universitario La Salle (Unitasalle), Porto Alegre, Brazil ${ }^{2}$ RWTH-Aachen, Lebr- und Forschungsgeblet Aufbereitung mineralischer Rohstoffe, Germany

${ }^{3}$ Universidade Federal do Rio Grande do Sul, Mineral Processing Laboratory, Porto Alegre, Brazil

*Corresponding author, emaif irneu.brum@ufrgs.br necessary for the removal of possible adherent substances from the minerals. After the drying, clectrostatic and magnetic separators are employed to generate concentrates of various heavy minerals, such as ilmenite, rutile, zircon and others. ${ }^{2,4}$

The relevance of zircon as a raw material is related to its chemical and physical properties, stch as high hardness and refraction index, melting point above $1800^{\circ} \mathrm{C}$ and others. ${ }^{2.3}$ These features favour the zircon's utilisation as a raw material in different industrial sectors, and the main applications are in ceramic products, melting and refractories. In Brazil, the average cost of a superior quality zircon concentrate is about $\$ 290$. In the international market, the same product costs $\$ 350 /$ ton. $^{5}$

In the zircon crystal lattice, a process known as metamictisation occurs, which consists on the replacement of $\mathrm{Zr}$ by other chcmical elements. Smith et al. ${ }^{6}$ verified that the zircon's structure can accommodate external ions in the process and in some grains, the authors found that $40 \%$ of all $\mathrm{Zr}$ content was replaced by $\mathrm{Y}, \mathrm{Th}, \mathrm{Nb}, \mathrm{U}$ and $\mathrm{Ca}$ cations, among others, and that a low amount of silicon was replaced by aluminium and phosphorus. Gorz and White ${ }^{7}$ showed that the iron enters the crystal lattice replacing silicon, and that its concentration can vary between 400 and $15000 \mathrm{ppm}$. Hartmann et $a l .,{ }^{s}$ in a study with metamictic zircons from the Caçapava granite, in Southern Brazil, identified chemical exchanges between the zircon and the metamorphic environment, and found that the metamictised portions were strongly enriched in $\mathrm{Fe}(\times 100)$ and in other elements.

The Millennium Company's deposit, known as Guaju Mine, is located in the municipality of Mataraca, in Paraiba State, NE Brazil. The main mineral good 
produced is ilmenite. Zircon and rutile are byproducts The heavy minerals are disseminated in mineral sands deposits, as $30 \mathrm{~m}$ high dunes (mean value). The mining takes place by mechanical dismounting (bucket wheel dredge) and the mincral processing occurs in gravity, electrostatic and magnetic devices.

Studies made by Sabedot and Sampaio ${ }^{9}$ on the deposit have indicated that $98 \%$ of the mincrals in the base of the dunes are opaque due to the existence of a strongly adhered pellicle. On the top of the deposit, conversely, around $95 \%$ of the minerals have a vitreous glow and there is no pellicle on the particles. After the characterisation, Sabedot and Sampaio ${ }^{10}$ applied an attrition process to the zirconite B concentrate, in laboratory scale, to optimise the operation parameters and the removal of pellicle. The process was efficient and removed the pellicle adhered to the minerals. The attritioned product was passed by the electrostatic and magnetic separators once again and the majority of the contaminant minerals were removed, yielding a high $\mathrm{ZrO}_{2}$ product,

In the ore processing, zircon concentrate is obtained from a current name zircon preconcentrate (PCZ), which is the reject from the ilmenite concentration. From the mineralogical point of view, it is a material with more than $80 \%$ in zircon, contaminated by rutile, ilmenite, cyanite, staurolite and others. The quality of PCZ varies according to the portion of the deposit being mined: if the works are in the base, the majority of the heavy minerals will present the adhered pellicle. This phenomenon will not appear if the top sediments are those being extracted. In the first case, the beneficiation of PCZ will yield low quality zircon concentrates and in the second one, high quality products will be generated.

The PC7 is processed by batches, in concentrating tables, elcctrostatic and magnetic separators. Zircon is a non-conducting and non-magnetic mineral. The pellicle around the mineral reduces the efficiency of electrostatic and magnctic devices in the separation of the contaminants. As a consequence, part of those is incorporated in the zircon rich fraction what results in a low quality final product.

Considering that the PCZ is the main source of all the concentrates produced at the Guaju Minc, an operation in the semipilot scale was conducted to verify if the results with the attrition experiments in laboratory would reproduce in a largest scale. The attritioned PCZ was then processed in the electrostatic and magnetic devices, and the results are commented in this paper.

The mineralogical characteristics of the Guaju's zircons also determine the yielding of low quality concentrates. Studies conducted with these concentrates indicate that several zircons contain mincral inclusions of variable dimensions.

Zircon is a mineral often utilised in the detection of rocks. One of the aspects referred in the literature is a process named metamictisation, which disorientates the zircon's crystal structure and incorporates alien substances to it. The low quality concentrate was also investigated in relation to the occurrence of this process.

Since mineral inclusions also determine the final quality of the zircon concentrate, physical procedures were tested on the PCZ to evaluate the performance in the operations of heating, milling and removal of inclusions. The results of these investigations are also presented and discussed in this paper.

\section{Materials and methods}

\section{Attrition in the PCZ}

Twelve $40 \mathrm{~kg}$ samples of $\mathrm{PCZ}$ were tested in semipilot attrition equipment. The tests and results in laboratory scale were optimised: concentration of solids in the pulp, concentration of $\mathrm{NaOH}$ in the pulp and stirring time. In Table 1, the parameters' values according to the runs are listed. Run 1 was executed without $\mathrm{NaOH}$ becaluse the company, duc to environmental issues, wanted to know about the performance without the chemical.

Aliquots of the attritioned products were analysed in the binocular magnifying lens and subjectively qualified in relation to the presence of grains with the adhered pellicle. So, the performance of the experiments was qualified as regular, good or outstanding.

To corroborate the efficiency of the treatment made, the spectrim of reflectance was measured, with a Minolta CM 508d spectrophotometer coupled to the OJ Holder accessory, in three samples: PCZ (without attrition) and runs 7 and 11 of the attrition studies. Each sample was meisured 11 times and the results were submitted to a statistical treatment $(t$ test $){ }^{11}$ to determine the difference between two mean values, considering the same variance for the samples, in a level of confidence equal to $95 \%$. Considering that the clayeyferruginous pellicle gives the grain's surface a reddish colour and an opaque appearance, the pellicle's removal alters the colour of the attritioned material and as a consequence, also the values of the colorimetric parameters are altered in the sample, before and after the attrition procedure.

The performance of the runs with and without the addition of $\mathrm{NaOH}$ was verified in attritioned samples (runs 1 and 5), tested in electrostatic and magnetic equipments. The electrostatic separator utilised was a Carpco, model HT 111-15, with a 14 in. induced roll. The wet magnetic separator was an Inbras/Eriez, model $4 \mathrm{~L}$, with a $2 \times 4 \mathrm{~mm}$ matrix, operating in a closed gap with $17000 \mathrm{G}$. The chemical analyses of the PCZ and the products of beneficiation were made in a Philips $X$ ray spectrophotometer, model PIVI660.

Samples from the reject of the attrition process were separated, dried and analysed in a Philips X-ray diffractometer to identify the mineral phases present in

Tabje 1 Operation parameters in PCZ attrltion tests (semipilot scale)

\begin{tabular}{llll}
\hline Run & Pulp, \% solids & $\mathrm{NaOH}, \mathrm{g} \mathrm{t}^{-\mathbf{r}}$ pulp & Time, min \\
\hline 1 & 80 & 0 & 20 \\
2 & 80 & 400 & 20 \\
3 & 80 & 400 & 40 \\
4 & 80 & 500 & 20 \\
5 & 80 & 600 & 20 \\
6 & 70 & 500 & 20 \\
7 & 70 & 600 & 20 \\
8 & 80 & 500 & 30 \\
9 & 80 & 600 & 30 \\
10 & 70 & 500 & 30 \\
11 & 70 & 600 & 30 \\
12 & 80 & 600 & 10 \\
\hline
\end{tabular}


the pellicle. Once dricd, the samples appeared like a clayey brown mass.

\section{Mineral inclusions}

Approximately 300 zircon grains with mincral inclusions were selected from a sample of the zirconite B concentrate for the mineralogical characterisation of the inclusions. After the selection, the grains were collated on a glass support and abraded, exposing 68 mineral inclusions that were photographed and analysed under an optical microscope and under an analytical microprobe.

\section{Metamictisation}

The metamictisation process was investigated in around 800 grains of the zirconite B concentrate, randomly collected. The grains were pasted on a glass support and then they were abraded and coated with graphite for analysis in a SX50 Cameca electron microprobe.

\section{Physical treatments in the zirconite $B$ concentrate}

The mineral inclusions in the zircons determine the elevated contents of contaminant substances in the zirconite B concentrate. Physical treatments, such as heating in the microwave oven, milling, electrostatic and magnetic separation, were implemented in the concentrate, to evaluate the performance in the removal of inclusions, by analysis after the treatments.

\section{Heating in the microwave oven}

The use of the microwave oven in the heating of the zircon's concentrate wats considered due to the discussions by Haque ${ }^{12}$ and Kingman and Rowson, ${ }^{13}$ in their reviews on the microwave energy in ore processing technologics. According to these researchers, the heating of minerals varies according to their chemical compositions and physical properties. Generally, metallic minerals, such as pyrite, heated by microwaves for $7 \mathrm{~min}$, can reach temperatures above $1000^{\circ} \mathrm{C}$. The temperature for non-metallic and transparent minerals, such as quartz, under the same conditions and time of exposure, remains close to $80^{\circ} \mathrm{C}$. Still according to the cited authors, the quick heating with microwaves is important for the release of economic minerals associated with a mineral gangue. Owing to the difference between the mineral's dilatation coefficients, microwaves act to provoke a fracture network in the contact zones between the different minerals and make their separation easier, in a posterior step of grinding and milling. Since zircon is a transparent mineral, the microwave oven was utilised to cause the fracturing in the zones of contact between the mineral and the inclusions. The operation parameters were: power $500 \mathrm{~W}$, heating time 7 min and mass of sample per batcl $600 \mathrm{~g}$.

\section{Milling}

Milling was utilised to promote the breakage of the inclusion bearing zircons, previously fractured by the microwave's action and thus the release or exposure of the inclusions. An impact mill was used, with continuous feed and withdrawal of material, designed to avoid the excessive comminution of the material. After the milling, the material was sieved at $0.063 \mathrm{~mm}$. The retained fraction was processed in electrostatic and magnetic equipments. The passing fraction, with a size distribution inadequate to the opcration in the mentioned equipments, was just chemically analysed.

\section{Electrostatic and magnetic separation}

The fraction $+0.063 \mathrm{~mm}$ was initially treated in the Corona type Krupp Laboratory electrostatic separator. Operation parameters were $30 \mathrm{kV}$ and roll rotation of $100 \mathrm{rev} \mathrm{min}^{-1}$. The non-conducting fraction was treated in a Carpeo induced roll magnetic separator, model MIH-13-111-5. The equipment was regulated at its maximum magnetic intensity and with the roll speed set to $33 \mathrm{rev} \mathrm{min}^{-1}$.

\section{Chemical analysis}

From all the steps in the processes, samples were taken to the chemical analysis, conducted in a Philips X-ray spectrometer, model PIVI660. The following oxides were determined: $\mathrm{Fe}_{2} \mathrm{O}_{3}, \mathrm{TiO}_{2}, \mathrm{ZrO}_{2}, \mathrm{Al}_{2} \mathrm{O}_{3}$ and $\mathrm{P}_{2} \mathrm{O}_{5}$.

\section{Results and discussion \\ Attrition on the $\mathrm{PCZ}$ \\ Subjective evaluation}

In a subjective evaluation, the performance of the attrition studies was qualificd as regular, good or outstanding. The regular performance indicated the presence of grains with clay adhered to shallow or deep cavities, or grains with remains of pellicle, and/or grains with opacity. Runs 1, 6 and 12 in Table 1 received this qualification. The good performance indicated the presence of grains with clay adhered only in some deep cavities, but without remains of pellicle and opacity. Runs 2-5, 7 and 10 in Table 1 were qualified as good. The outstanding performance indicated that the gains were entirely free from pellicle or clay, with shining surfaces. Runs 8,9 and 11 in Table 1 fell into this qualification.

In the global evaluation of results, the parameters from these runs qualified as good were admitted as ideal values (runs 2, 4, 5 and 7), due to the smaller operation times. Run 7, with a smaller concentration of solicts in the pulp, could be elected as the most adequate of all, if this parameter represents diminished energy consumption, but this aspect was not evaluated in the tests. Although runs 8,9 and 11 presented an outstanding performance, their operation times were considered too long for the process. Runs 1, 6 and 12 were not efficient in the removal of the pellicle, which indicates that the operations without $\mathrm{NaOH}$ (run 1) or with a 10 min residence time (run 12) were far from the ideal. Run 6 presented an atypical result, probably as a consequence of some operation problem that was not detected during the experiment.

\section{Objective evaluation}

The chemical analysis by $X$-ray fluorescence proved to be inadequate to evaluate the results, becatse the pellicle's mass removed by attrition was of little significance, if compared with the original PCZ mass. The results of analyses made before and after the attrition showed differences that coincide with the values of the confidence limits of the analytical method (margin of error) and due to this fact, the colorimetric method was selected as the objective tool to evaluate the process.

In Table 2, the values of mean and standard deviation for brightness and yellowness are listed (calculated by 


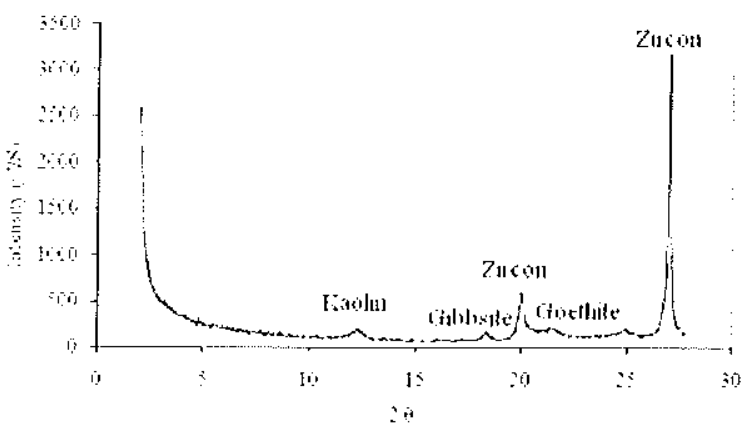

1 Diffractogram of reject of attrition

the ISO 2470 and ASTM E313 norms respectively), referring to the statistical treatment of $\mathrm{PCZ}$, run 7 and run 11 samples. The statistical treatment included a $t$ test to compare the mean values obtained in runs 7 and 11 in relation to the PCZ sample. The $t$ values and the associated probabilities can equally be found in Table 2 . Both the $t$ values, above the critical value of $2 \cdot 05$, which corresponds to a $95 \%$ confidence interval, and the $p$ values, below $0 \cdot 1 \%$, confirm that both treatments werc effective both in the increase in brightness and in the decrease in the yellowness in the studied samples.

\section{Reject of the attrition}

The mineralogical analysis of the reject of the attrition experiments identified peaks of kaolinite, gibbsite, gocthite and zircon, as shown in the diffractogram from Fig. 1. The first three peaks characterise the pellicle's composition and are typical of the natural alteration processes that occur in the sediments, mainly when submitted to the percolation of water, either by the phreatic as by the infiltration. The peaks for zircon in the diffractogram represent torn fragments of zircon and/or zircon powder, resulting from the comminution caused by intergranular shocks occurring during the process.

\section{Attrition with and without the use of $\mathrm{NaOH}$}

The less efficient performance in the semipilot attrition process was identified in run 1, conducted withont the addition of $\mathrm{NaOH}$. A comparative test applied to the attritioned products from this run and from run 5 has shown, in a qualitative way, that the use of the chemical is important in the attrition process. Aliquots from these runs were processed in the electrostatic and magnetic separators, in this sequence. The final, the nonconductor and non-magnetic portion of each aliquot, were analysed by $X$-ray fluorescence. Table 3 shows the results. The PCZ sample refers to the non-attritioned product and the samples' 'run I' and 'run 5' refer to the attritioned fractions, processed in the elcetrostatic and magnetic separators. Rutile and ilmenite are the main

Table 2 Statlstical comparison of measured colorimetric parameters

\begin{tabular}{|c|c|c|c|c|c|c|}
\hline & \multicolumn{3}{|c|}{ Brightness } & \multicolumn{3}{|c|}{ Yellowness } \\
\hline & $\mathrm{PCZ}$ & Run 7 & Run 11 & $\mathrm{PCZ}$ & Run 7 & Run 11 \\
\hline Mean & $16 \cdot 77$ & $17 \cdot 31$ & $17 \cdot 75$ & 28.91 & 26.24 & $26 \cdot 82$ \\
\hline Standard deviation & 0.34 & 0.32 & 0.42 & 0.90 & $1 \cdot 60$ & 1.38 \\
\hline$t$ & & $3 \cdot 87$ & 5.98 & & 4.84 & $4 \cdot 23$ \\
\hline$p$ value, \% & & 0.041 & 0.001 & & 0010 & 0.096 \\
\hline
\end{tabular}

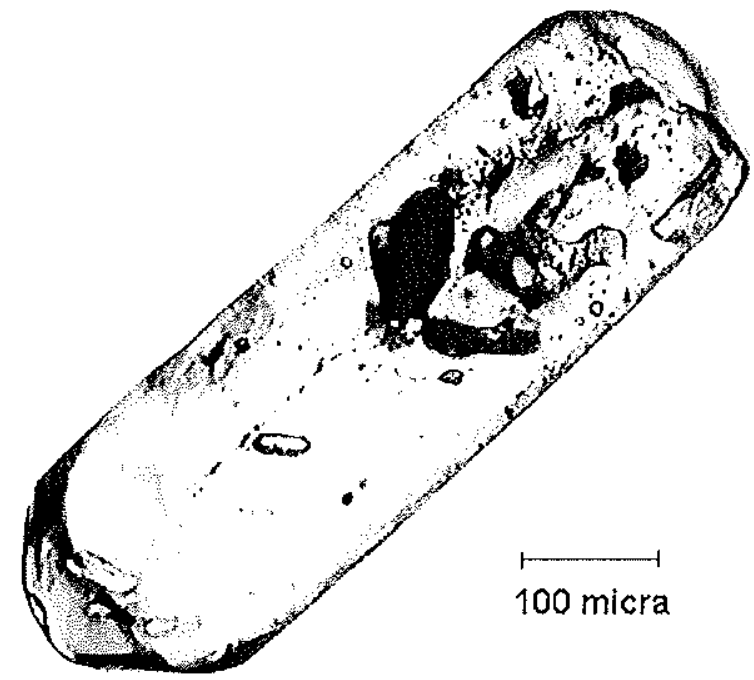

2 Mineral inclusions in zircons from low quality concentrate

contaminants for the PCZ. The values for $\mathrm{TiO}_{2}$ presented more significant differences between the samples processed with and without $\mathrm{NaOH}$, and there is around $100 \%$ more $\mathrm{TiO}_{2}$ in the product attritioned without $\mathrm{NaOH}$. For the remaining oxides, the differences fall within the operational range of error of the equipment.

Generally, the results of semipilot attrition tests evidenced that the operational performances were similar to those obtained in the laboratory scale. Considering the simplicity and the efficacy of the attrition process, it appears to be a viable alternative to be introduced in the industrial scale at the Guaju mine, objectively to the $\mathrm{PCZ}$ product, to promote the production of zircon concentrates of higher purity.

\section{Mineral inclusions}

Around $28 \%$ of the zircon from CZB presents a significant amount of mineral inclusions which can occupy a considerable volume of grains as shown in Fig. 2. By mineralogical study of inclusions, several species were identified (Table 4) among which the magnetic ones, the biotite, the quartz and the ilmenite are the most abundant ones. These minerals, without considering the quartz, represent around $50 \%$ of the mass of the inclusions.

Analysis of inclusions in five magnetic minerals, carried out by SEM, showed that around $60 \cdot 2 \%$ of the mass, on the average, corresponds to the iron element. Inclusions in biotite and ilmenite have, on the average, 30.2 and $46.1 \% \mathrm{FeO}$ respectively. On the other hand, apatite is the fifth more frequent mincral species found as inclusion. In addition, $\mathrm{Al}_{2} \mathrm{O}_{3}$ can be found as inclusion in biotite, feldspar and plagioclase. Inclusions may represent an important contaminant fraction of the

Table 3 Chemical analyses (\%) for PCZ and samples attritioned with and without $\mathrm{NaOH}$, processed in electrostatic and magnetic equipments

\begin{tabular}{lccccc}
\hline Sample & $\mathrm{TiO}_{2}$ & $\mathrm{Fe}_{2} \mathrm{O}_{3}$ & $\mathrm{P}_{2} \mathrm{O}_{5}$ & $\mathrm{Al}_{2} \mathrm{O}_{3}$ & $\mathrm{ZrO}_{2}$ \\
\hline $\mathrm{PCZ}$ & 7.46 & 1.49 & 0.19 & 1.31 & 58.36 \\
Run 1: without NaOH & 0.65 & 0.24 & 0.12 & 1.09 & 66.17 \\
Run 5: with NaOH & 0.30 & 0.28 & 0.11 & 1.07 & 66.03 \\
\hline
\end{tabular}



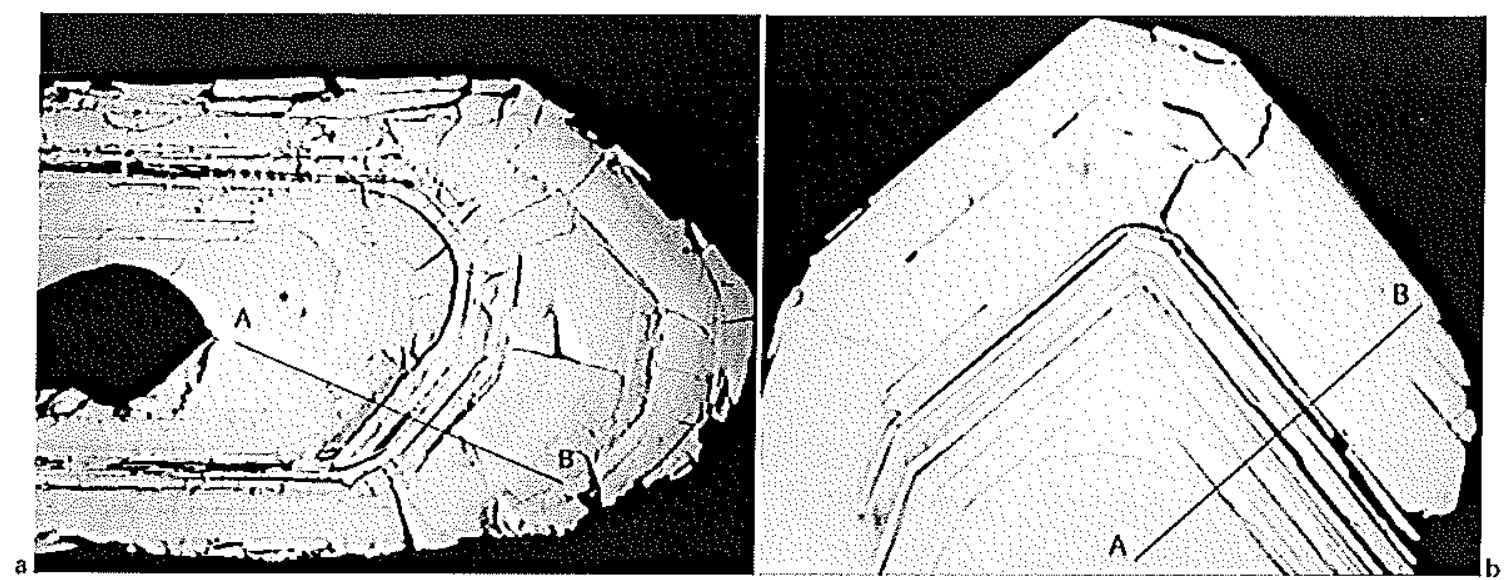

$a$ highly fractured; $b$ slightly fractured

3 Images (BSE) of zircons with metamictisation bands

CZB and may explain the fact that after purification, PCZs present high grades of $\mathrm{Fe}_{2} \mathrm{O}_{3}, \mathrm{P}_{2} \mathrm{O}_{5}$ and $\mathrm{Al}_{2} \mathrm{O}_{3}$ rendering them low quality products.

\section{Metamictisation}

Metamictisation process produces alteration which modifies the zircon chemical composition. The process is carried out in two ways: by the transformation of the elements of the crystal lattice during the process and by the ulterior alterations provoked by solutions which penetrate the mineral through fractures originated during the process.

Figures 3 shows the spectra of the elements $\mathrm{Fe}$, Th and $\mathrm{Zr}$ in the structures of two zircon grains picked at random. In each grain, the spectra show that in the dark bands (metamictised areas of the mineral), Fe and Th concentrations appear high while $\mathrm{Zr}$ concentration appears low. On the other hand, in the clear bands (areas not metamictised), it appears the contrary, i.e. Fe and $\mathrm{Th}$ concentrations appear low and that of $\mathrm{Zr}$ appears high.

This characterisation does not allow determining absolute values of alterations in the concentrations of the elements inside the grains. Nevertheless, from the spectra, it can be inferred that alterations must be considerable. For example, in the spectrum corresponding to $\mathrm{Zr}$ (Fig. 4) which corresponds to the zircon sample of Fig. 3a, the $\mathrm{Fe}$ counts of clear bands is $\sim 2500$, while in the dark bands, it is around 32000 . For

Table 4 Mineral inclusions in zircons, identified by analytical microprobe

\begin{tabular}{lcc}
\hline Inclusions & Total & \% Grains \\
\hline Magnetic & 14 & 21 \\
Biotite & 13 & 19 \\
Quatz & 10 & 15 \\
Ilmenite & 7 & 10 \\
Apatite & 6 & 9 \\
Oxide Te-Ti & 4 & 6 \\
Feldspar & 4 & 6 \\
Plagioctase & 3 & 4 \\
Titanite & 2 & 3 \\
Limonite & 2 & 3 \\
Copper minerals & 2 & 3 \\
Amphibole & 1 & 1 \\
Sum & 68 & 100 \\
\hline
\end{tabular}

Th, counts are around 2000 in the clear bands and around 15000 in the dark bands. In the contrary, $\mathrm{Zr}$ counts are around 100000 in the clear bands and drop down to around 63000 in the dark bands.

The spectra also indicate a variation between 60000 and 100000 counts for the Zr. However, the counts in the spectra of $\mathrm{Fe}$ and $\mathrm{Th}$ appear different in the grains. Those differences must be related to the intensity of the metamictisation process in the interior of the grain which produces more or less alteration of the $\mathrm{Zr}$ to some other element. Figure 5 illustrates the spectra of Fc, Th and $\mathrm{Zr}$ of the zircon sample shown in Fig. $3 b$. These results confirm the data of Hartmann $2 t a .^{15}$ and Nasdala et al. ${ }^{16}$ who concluded that the areas of zircons with high metamictisation degree generally contain high quantity of the trace elements and they are characterised by higher variations in the concentrations of those elements than in the neighbouring areas which are not metamictised.

Zircon fractures are related to the metamictisation according to Wopenka et $a l^{14}$ and Nasdala et $a l^{16}$ According to them, physicochemical variations during zircon growth produces non-uniform $U$ and Th concentrations in the mineral, causing volume expansions at different rates. In general, the regions rich in $U$ and $T h$ expand faster. Those heterogeneous expansions produce internal pressures throughout the mineral, high enough to produce fractures. Fractures become potential paths where fluids penetrate, allowing leaching of the elements. Figure 3 shows fractures which are common to the zircons analysed by SEM. Those characteristics lead one to conclude that metamictisation is also a factor which determines high grades of contaminant substances and hence a low quality of the raw $C Z B$ is produced in the Guaju Mine.

\section{Physical treatments on the zirconite $B$ concentrate}

Table 5 shows a mass balance and chemical analysis after physical processes were applied to CZB. Grinding was considered satisfactory because it generated low amount of fines. As the aim was to fiacture zircon glains carrying inclusions in order to liberate or to expose them, it was important to produce the less fine material due to restrictions in electrostatic or magnetic proccsses. After grinding, many broken grains were found; most of 

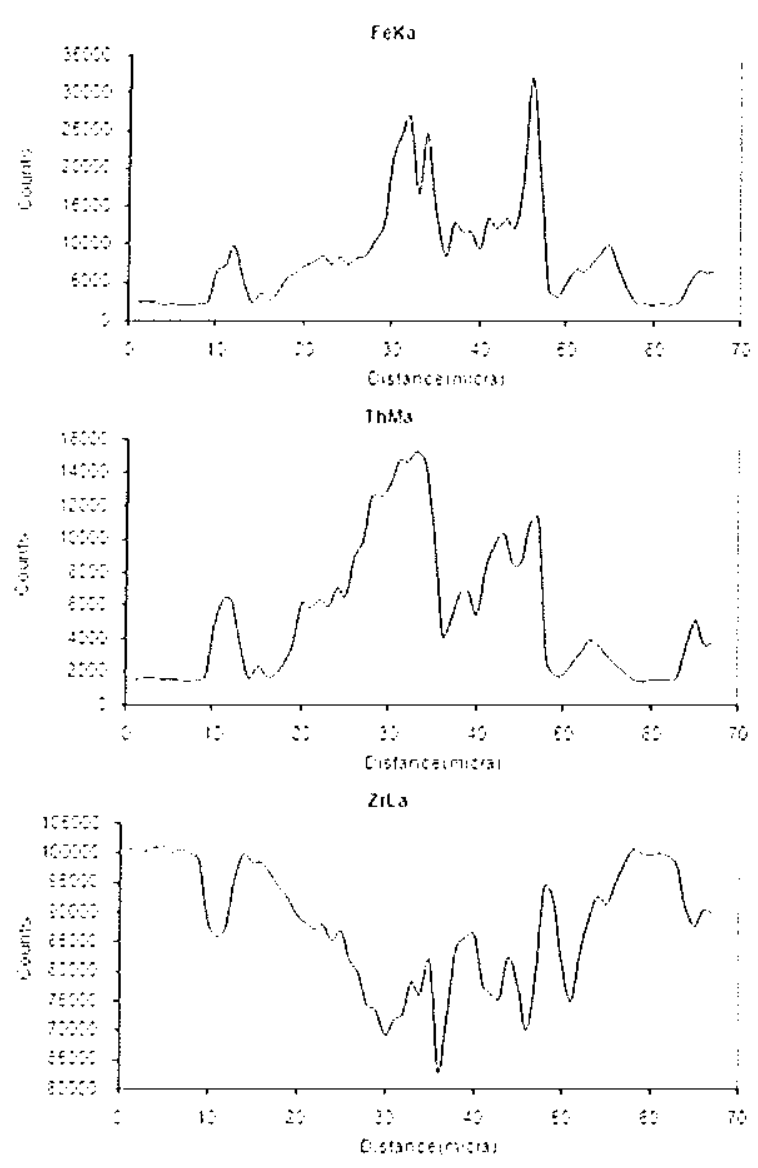

4 Spectra of distribution of $\mathrm{Fe}$, Th and $\mathrm{Zr}$, obtained by electron microprobe analysis, correspondent to $A B$ scanning shown in Fig. $3 a$

them were frec from inclusions, and some of them had the inclusions adhered but were exposed as the grains showed in Fig. 6.

In general, ground samples showed low number of gatains having big size inclusions. However, it appears that many grains have little size inclusions which appeared incorporated to the mineral. Those facts may indicate that microwave heating is adequate to liberate big inclusions but not so for little ones. High content of $\mathrm{Fe}_{2} \mathrm{O}_{3}$ and $\mathrm{P}_{2} \mathrm{O}_{5}$ in the $-0.020 \mathrm{~mm}$ size fraction (Table 5) also support the idea that heating/grinding processes are effective for liberating inclusions. Analysis of inclusions by SEM slowed that most part of inclusions is formed by minerals which contain mainly $\mathrm{Fe}$ and $\mathrm{P}$ in a minor extent. The inclusions appeared concentrated in the $-0.020 \mathrm{~mm}$ as a consequence of the processes heating/grinding.

The product $+0.063 \mathrm{~mm}$ separated by sieving, submitted to an electrostatic process, produced a low amount of conductive material $(5 \cdot 0 \%)$ and $80 \cdot 2 \%$ of non-conducting substance. This was considered as a positive factor due to the little amount that would be lost.

The manetic separation of the conducting material produced a relatively low amount of magnetic product $(3.4 \%)$ and a significant amount of mix fraction $(24 \cdot 6 \%)$. A reduction of the mean diameter $D_{50}$ of the original mass by grinding could have affected the performance of the equipment giving rise to a high volume of mix or
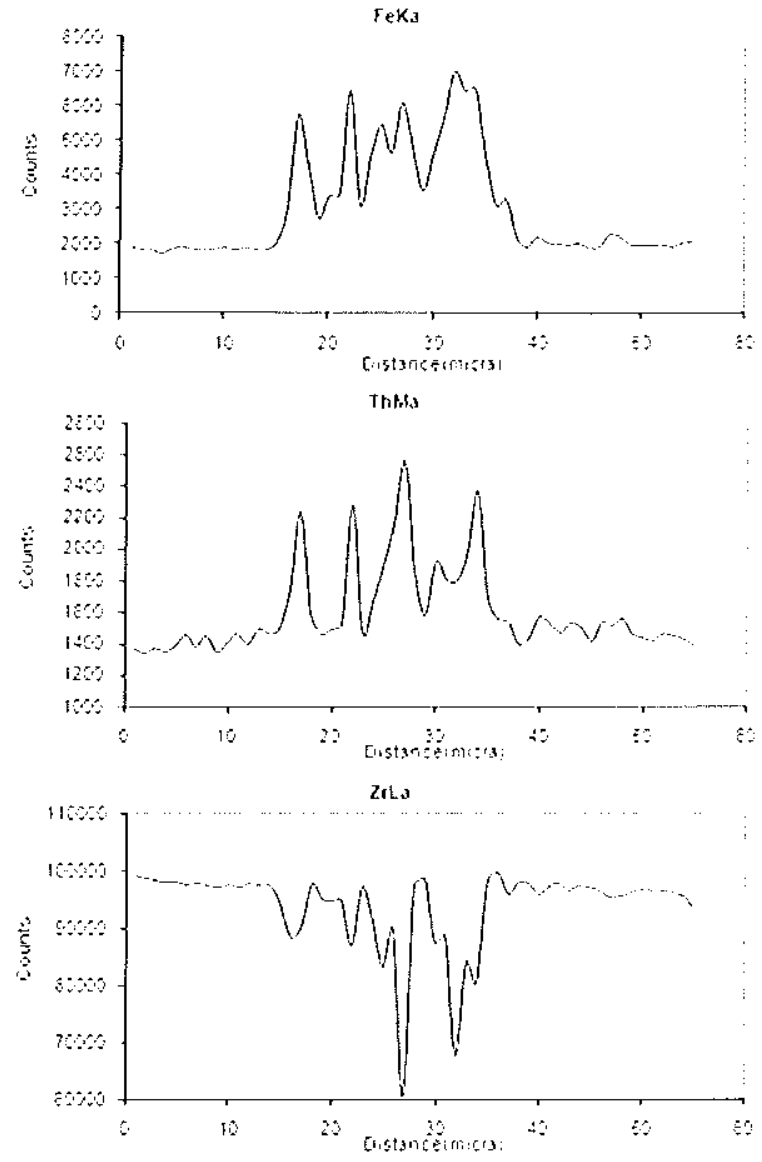

5 Spectra of distribution of $\mathrm{Fe}$, Th and $\mathrm{Zr}$, obtained by electron microprobe analysis, correspondent to $\mathrm{AB}$ scarning shown in Fig. $3 b$

could have been due to the exposure of the inclusions of the broken grains which allowed the separation of zircon grains having mineral inclusions.

The non-magnetic product was the final product. As a mass, the recovery of $52 \cdot 2 \%$ is considered poor. However, from quality standpoint, chemical analysis showed that the composition is very close to that of

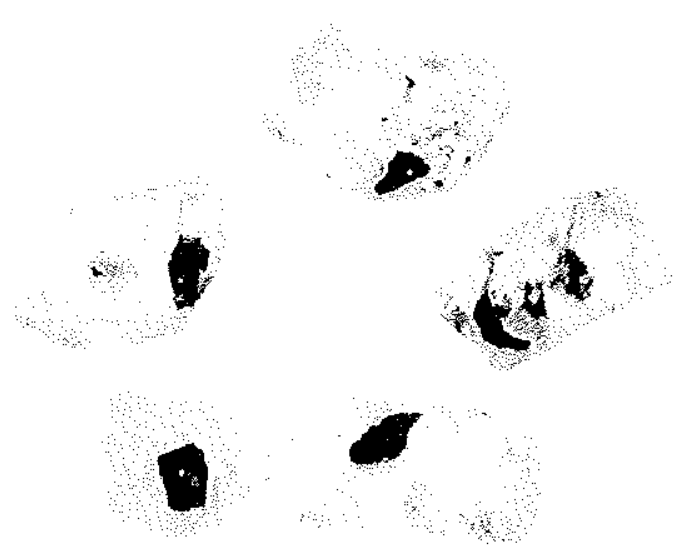

6 Zircons with exposed inclusions, after comminution and magnetic separation 
Table 5 Processes, mass balance and chemical analyses: zirconife $\mathbf{B}$ concentrate

\begin{tabular}{|c|c|c|c|c|c|c|c|}
\hline Process/product & & Mass, $\%$ & $\mathrm{TiO}_{2}$ & $\mathrm{Fe}_{2} \mathrm{O}_{3}$ & $\mathrm{P}_{2} \mathrm{O}_{5}$ & $\mathrm{Al}_{2} \mathrm{O}_{3}$ & $\mathrm{ZrO}_{2}$ \\
\hline Zirconite B concentrate sample & & 100 & $0 \cdot 69$ & $0 \cdot 27$ & 0.08 & 1.52 & $64 \cdot 1$ \\
\hline Sizing of zirconite 8 & $+0.063 \mathrm{~mm}$ & $85 \cdot 2$ & $0 \cdot 2$ & 0.17 & 0.08 & $1 \cdot 32$ & 64.56 \\
\hline Concentrate sample & $-0.020 \mathrm{~mm}$ & $2 \cdot 3$ & 0.19 & $2 \cdot 62$ & 0.25 & $1 \cdot 62$ & $62 \cdot 68$ \\
\hline \multirow[t]{2}{*}{ Electrostatic separation of $+0.063 \mathrm{~mm}$} & Conductor & $5 \cdot 0$ & $*$ & * & $*$ & $*$ & $*$ \\
\hline & Non-conductor & $80 \cdot 2$ & $0 \cdot 16$ & 0.17 & 0.08 & $1 \cdot 16$ & $65 \cdot 29$ \\
\hline Magnetic separation of non-conductor & Non-magnetic & $52 \cdot 2$ & 0.1 & 0.15 & 0.06 & 0.97 & 65.94 \\
\hline
\end{tabular}

*Sample not evaluated.

zirconite $E$, the best product produced in the Guaju Mine. As the product did not have the qualities of that product, it could be compared with zirconite $I$, also produced by the mine which represents a value of 5 in a scale from 1 to 6 in which the number 6 represents zirconite $E$ (zirconite $B$ has a value of 2 ). From here, it can be stated that the treatment implemented on the CZB produced a quality increase of 3 points leading to a considerable gain in quality as well as in commercial value. The product did not reach the value of 6 due to the contents of contaminant substances which surmount those found in zirconite $\mathrm{E}$, but the $\mathrm{ZrO}_{2}$ produced had at final value $1 \%$ above the minimum necessatry to get quality of 6.

\section{Conclusions}

1. The high contents of contaminants found in the zirconite $B$ concentrate are caused by three main product's characteristics:

(i) claycy-ferruginous pellicle in the PCZ obtained from the sediments mined at the base of the deposit. Some minerals, such as ilmenite, cyanite, rutile and monazitc, are impregnated by the pellicle and are not removed in the magnetic and electrostatic separations, remaining as contaminants in the zirconite $B$

(ii) mineral inclusions in around $28 \%$ of the zircons Most of the identified inclusions consist of minerals that present the contaminant substances to the zirconite $\mathrm{B}$

(iii) metamictisation in around $15 \%$ of the zircons: this is a process that causes the replacement of $\mathrm{Zr}$ by other elements, markedly Fe.

2. The attrition in the semipilot scale had performance similar to the tests in the laboratory scalc, proving that the operation parameters defined are optimised and that the attrition operation on the PCZ is important for the removal of the clayey-ferruginous pellicle that is impregnated in most of the grains from the inferior part of the deposit. The pellicle is constituted by kaolinite, gibbsite and goethite.

3. The physical treatments applied to the zirconite B concentratc were efficient in the removal of contaminants. The contents of $\mathrm{ZrO}_{2}$ and contaminants were very similar to those achieved in the zirconite $\mathrm{E}$ concentrate, a high quality product claborated at the Guaju operation.

4. The mass balance of the physical treatments carried out on the zirconite $B$ pointed at a mass recovery of $52 \cdot 2^{1 \%}$ as the final product (non-magnetic).
Commercially, this product can represent (in terms of weight), a value three times superior to that of zirconite $B$, because its chemical specifications are very close to the superior quality product also obtained at the Guaju Mine. The finer particle size, caused by the comminution, can represent a higher value aggregated to the final product. Besides the final product, the mixed $(24 \cdot 6 \%)$ and $-0.063,+0.020 \mathrm{~mm}(12.5 \%)$ fractions presented better contents than the zirconite $B$, and will probably present more attractive commercial values. The losses, or the products with commercial values smaller than the zirconite $B$ valuc, due to their chemical specifications, represent the conductor $(5.0 \%)$, magnetic $(3.4 \%)$ and $-0.020 \mathrm{~mm}(2 \cdot 3 \%)$ fractions.

\section{Acknowledgements}

The authors thank to the Millemium Inorganic Chemicals do Brasil S/A by the samples donated for the study, to the Professor L. A. Hartmann, from the Institute of Earth Sciences at the UFRGS, for the important information about the zircons and the metamictisation process, to the CAPES/PROBRAL/ DAAD Program, by the financial support to the study, to the Dr R. Gliese, fellow researcher at the LAPROM/ UFRGS, by the scientific support in the statistical evaluation procedures, to the AMR at the RWTH Aachen, by the technological support in the execution of the physical processes, to the Institute of Mineralogy at the RIVTH Aachen, by the technological support in the evaluation of mineral inclusions inside the zircons.

\section{References}

I. J. D. Dana: 'Handbook ol mineralogy'; 1978, São Paulo, Livros Técnicos e Científicos Editora S/A.

2. T. E. Garnar: in 'Industral minerals and rocks', 6th edn, (ed. D. D. Carr), 1159.1165; 1994. Littleton, $\mathrm{CO}$, Society for Mining, Metallurgy and Exploration Inc.

3. J. Gambogi: 'Zirconium and bafnium': 1997, Reston, VA, USGS.

4. H. V. Mutijen, and R. A. Massee: Proc. XVII Natl Meet. for Mincral Processing and Extractive Metallurgy. Aguas de São Pedro, Brisil, Augtst 1998.

5. DNPM: 'Sumário mineral'; 2002, Brasileiro, DNPM.

6. D. G. W. Simith, L. Jorre, S. J. B. Reed and J. V. P. Long: Cim. Hineral., 1991, 29, 301-309.

7. H. Gorz and E. W. White: Comtrih. Mineral. Po'trol, 1970, 29, 180182.

8. L. A. Hartmann, M. A. Z. Vasconcellos and A. P. Rosa: Pesquises, 1999, 26. (1). 59-66.

9. S. Sabedot and C. H. Sampaio: Pros. 551h Cong. Antial dia ABM, Rio de Janciro, Brasil, July 2000, ABM, Vol. 1, no. 1, 525533.

10. S. Sabedol and C. H. Simpaio: Proc. VI Mcet, of the Southern Hemisphere on Mineral Techonoly/XYIII Encontro Nacional de 
Tratamento de Minćrios e Metalurgia Extrativa, Rio de Janeiro, Brasil, May 2001, CETEM/MCI, Vol. 3, 79-82.

11. Walpole and R. H. Myers: 'Probability and statistics for enginecrs and scientists', 5th edn; 1993, New York, Macmillan Publishing Company.

12. K. F. Haque: Int. I. Miner. Process, 1999, 57, 1--24.

13. S. W. Kingman and N. A. Rowson: Mimer. Eing., 1998, 11, (11), I0St-1087.
14. B. Wopenka, B. L. Jolliff, E. Zinner and D. T. Krenser: $d m$. Mincrul., 1996, 81, 902-.912.

15. I. A. Hartmann, J. A. D. Leite, L. C. da Silva, M. V. D. Remus, N. J. McNaughton, D. I. Groves, I. R. Fletelier, J. O. Santos and M. A. Z. Vasconcellos: Just. J. Eurth Sici, 2000, 47, 829 844.

16. L. Nasdala, R. T. Pidgcon and D. Wof: Gowhim. Cosmochim. dckl, 1996, 60, (6), 109]-[097. 